\title{
Strategi Pengembangan Budidaya Jamur Tiram Di Kabupaten Magetan
}

\author{
Widita Nareswari ${ }^{1}$, Abu Talkah $^{2}$, Ahsin Daroini $^{3}$ \\ ${ }^{1}$ Magister Agribisnis Universitas Islam Kadiri, Jl. Sersan Suharmaji No. 38 Kediri, 64128 \\ E-mail: win.widita@gmail.com \\ ${ }^{2}$ Dosen Universitas Islam Kadiri, Jl. Sersan Suharmaji No. 38 Kediri, 64128 \\ E-mail: abutalkah@uniska-kediri.ac.id \\ ${ }^{3}$ Dosen Universitas Islam Kadiri, Jl. Sersan Suharmaji No. 38 Kediri, 64128 \\ E-mail: daroiniahsin30@gmail.com
}

\begin{abstract}
Magetan Regency which is located in the western end of East Java Province geographically has the potential in agriculture in the development of horticultural commodities namely oyster mushrooms. Oyster mushroom cultivation in Magetan Regency is relatively new with supporting factors such as affordable raw materials; cultivation techniques that are easy to learn; and humidity factors that support but have weaknesses, one of which is capital; farmer's motivation and tenacity; and the absence of technology application. Based on these conditions, this study aims to: (1) Identify and analyze internal and external factors that influence the development of oyster mushroom agribusiness in Magetan Regency (2) Formulate alternatives and recommend priorities for the development of oyster mushroom in the Regency Magetan. This research uses SWOT analysis and Process Hierarchy Analysis (AHP). The results showed the influential factors that obtained the highest score factors were organic crops, limited capital, motivation and persistence of farmers, public awareness of healthy food, weather and pests. Whereas the alternative that has the highest three priority values is to increase the number of baglogs along with the quality of the baglog quality of mushroom seeds, the application of appropriate management and human resources, and expand the reach of market share and the use of technology in marketing.
\end{abstract}

Keywords—: Oyster mushrooms; SWOT; AHP.

\section{PENDAHULUAN}

Di tengah era globalisasi seperti sekarang, jumlah penduduk yang semakin bertambah berbanding terbalik dengan semakin berkurangnya peluang kerja. Masyarakat memilih untuk melakukan usaha sendiri baik perseorang maupun berkelompok. Hal ini berdasarkan data Badan Pengawasan Statistik (BPS) pada Data Sensus Penduduk tahun 2010, Jumlah penduduk Indonesia pada tahun 2010 adalah sebanyak 237641326 jiwa, yang mencakup mereka yang bertempat tinggal di daerah perkotaan sebanyak 118320256 jiwa (49,79\%) dan di daerah perdesaan sebanyak 119321070 jiwa (50,21\%). Pertumbuhan penduduk yang semakin meningkat memberi dampak dengan jumlah pengangguran setiap tahun berfluktuasi dari tahun 2016 bulan februari sebesar 5,50 \% dan agustus sebesar 5,61 \% sedangkan pada tahun 2017 bulan februari sebesar 5,33 \% (BPS, 2019).

Berbagai macam usaha sekarang telah digalakan oleh pemerintah guna meningkatkan pendapatan masyarakat. Seperti halnya pengembangan UMKM hingga saat ini jumlahnya telah menggelembung sedemikian besar bahkan hampir menyamai jumlah mereka yang bekerja disektor formal lainnya (Gunawan dan Permadi, 2015). UMKM berkembang salah satunya pada sektor pertanian. Komoditas pertanian semakin berkembang dengan adanya kesadaran masyarakat akan pentingnya berbagai hasil pertanian bagi keberlangsungan hidup sehingga sekarang ini dibudidayakan masyarakat dan bersifat potensial (Rompas dkk, 2015).

Sektor pertanian merupakan aset penting bagi Indonesia yang mempunyai peran strategis dalam pertumbuhan ekonomi nasional dikarenakan 1) sebagai ladang mata pencarian masyarakat sebagai petani, 2) memberikan peluang kerja guna mengurangi tingkat pengangguran, 3) menyediakan bahan pangan dan bahan baku industri, 4) peningkatan ekspor sebagai devisa negara, 5) mengembangkan potensi sumber daya khususnya manusia baik secara politik, ekonomi, sosial, budaya dan lingkungan serta 6) peningkatan kesejahteraan masyarakat dan petani (Iqbal dan Sudaryanto, 2008; Rompas dkk, 2015). Oleh karena itu, perlu adanya pengembangan usaha dan produk di dalam sektor pertanian agar mampu meningkatkan pemerataan pertumbuhan dan perekonomian di Indonesia bahkan mampu menaikan status petani menjadi pelaku usaha (Tirani dkk, 2018).

Salah satu komoditas pertanian yaitu holtikultura pada tanaman pangan (Prastowo, 2007). Tanaman pangan dibudidayakan di Kabupaten Magetan oleh petani yang sebagian besar sebagai mata pencarian utama. Tanaman pangan yang masih tergolong baru disini adalah budidaya jamur tiram. Memiliki sektor lahan dan faktor lingkungan yang berpengaruh pada jamur tiram, hal ini dimanfaatkan oleh masyarakat Magetan untuk memulai bisnis budidaya jamur tiram. Bisnis ini memberi peluang petani di Magetan, untuk dikembangkan sebagai pekerjaan sampingan bahkan beberapa petani jamur menjadikan pekerjaan utama.

Budidaya jamur menjadi inovasi baru untuk petani maupun warga di Kabupaten Magetan untuk meningkatkan sendi perekonomian (Fatria, 2017; Sumarsih, 2010; Suriawiria, 2002; Mayanja dan Tipi, 2018). Tetapi dalam pelaksanaannya masih 
Website : http://agritek.unmermadiun.ac.id/index.php/agritek

dibutuhkan faktor-faktor penunjang untuk keberhasilan budidaya. Faktor-faktor penunjang bisa disesuaikan pada keadaan wilayah masing-masing. Wilayah Magetan masih banyak diperlukan alternatif faktor apa saja yang mendukung budidaya jamur tiram. Manajemen dan strategi yang tepat diharapkan mampu memberikan dampak positif dalam bekerlangsungan budidaya jamur tiram, hal ini dikarenakan faktor-faktor penunjang saling berkaitan dan berhubungan, faktor internal dan eksternal pada budidaya jamur tiram diidentifikasi sehingga menjadi pertimbangan petani (Retnaningsih dan Bambang, 2017) dan menentukan alternatif strategi untuk menentukan prioritas strategi yang akan diimplementsikan untuk pengembangan budidaya jamur tiram (Evalia, 2015).

Tujuan pada penelitian ini yaitu (1) Mengidentifikasi dan menganalisis faktor internal dan faktor eksternal yang berpengaruh pada pengembangan agribisnis jamur tiram di Kabupaten Magetan (2) Merumuskan alternatif dan merekomendasikan prioritas strategi pengembangan jamur tiram di Kabupaten Magetan.

\section{METODE PENELITIAN}

Penentuan lokasi pada penelitian ini dilakukan secara purposive sampling yaitu penentuan lokasi dipilih secara sengaja (Yani, 2011) disesuaikan dengan tujuan (Alie, 2011) di wilayah Kabupaten Magetan yang memiliki usaha budidaya jamur tiram. Pengambilan sampel dalam penelitian ini menggunakan metode purposive sampling (Rahajuningsih, 2011) yang digunakan untuk memilih responden. Responden yang dijadikan sebagai sampel adalah key person (Jumna, 2015) sebanyak 13 petani jamur tiram.

Metode analisis data yang digunakan yaitu analisis kualitatif menggunakan analisis SWOT dan analisis kuantitatif yaitu Analisis Hirarki Proses (AHP). Analisis SWOT digunakan untuk mengidentifikasi dan menganalisis faktor eksternal dan faktor internal serta merumuskan strategi yang tepat untuk budidaya jamur tiram dalam mencapai tujuan. Sedangkan Analisis AHP yang digunakan menetukan prioritas strategi pengembangan budidaya jamur tiram.

Langkah-langkah analisis dalam penelitian ini adalah sebagai berikut :

1. Tahap pengumpulan data dengan menyusun matriks IFE ini terdiri dari empat kuadran yaitu kekuatan dan kelemahan dari faktor internal. Kuadran peluang dan ancaman dari faktor eksternal.

Penilaian bobot berkisaran antara 1,0 (sangat setuju) sampai dengan 0,0 (tidak penting). Menentukan skala dengan ukuran sangat setuju, setuju, kurang setuju, tidak setuju dan sangat tidak setuju. Penberian nilai skala untuk faktor kekuatan dan peluang bersifat positif (kekuatan atau peluang semakin besar diberi skala +4 tetapi jika kecil maka diberi skala +1 ) Pemberian nilai skala kelemahan dan ancaman bersifat kebalikannya misalnya, jika nilai kelemahan atau ancaman sangat besar maka skala yang diberikan adalah 1 sebaliknya jika nilai kelemahan dan ancamannya sedikit maka skala yang diberikan adalah 4 (Rahajuningsih, 2011: Utsalina dan Weda, 2015).

2. Sedangkan hasil matrik IFE kemudian dianalisis untuk didapatkan posisi pemetaan usaha saat ini.

3. Menyusun matriks SWOT untuk mengetahui rumusan strategi dari penggabungan faktor SO, WO, ST dan WT.

Hasil beberapa rumusan alternatif strategi dari matrik SWOT kemudian diaalisis menggunakan analisis AHP yang digunakan untuk menentukan prioritas strategi pengembangan budidaya jamur tiram. Pengolahan data dan perhitungan dengan metode ini dibantu dengan menggunakan software expert choice 11

\section{III.HASIL DAN PEMBAHASAN}

Matrik IFAS yaitu matrik faktor internal untuk merumuskan faktor internal dalam kekuatan dan kelemahan. Hasil matrik IFAS sebagai berikut :

Tabel 1. Matrik IFAS

\begin{tabular}{|c|c|c|c|c|c|}
\hline \multirow{2}{*}{\multicolumn{3}{|c|}{$\begin{array}{l}\text { FAKTOR - FAKTOR INTERNAL } \\
\text { A. KEKUATAN }\end{array}$}} & \multirow{3}{*}{$\begin{array}{c}\text { BOBOT } \\
\text { (a) }\end{array}$} & \multirow{2}{*}{$\begin{array}{l}\text { RATING } \\
\text { (b) }\end{array}$} & \multirow{2}{*}{$\begin{array}{l}\text { SKOR } \\
(\mathbf{a} \times \mathbf{x})\end{array}$} \\
\hline & & & & & \\
\hline \multirow[t]{8}{*}{1.} & \multirow[t]{8}{*}{ BAHAN BAKU } & - Bahan baku mudah didapat & & 3 & 0,09 \\
\hline & & - Bahan baku terjangkau transportasi & 0,03 & 3 & 0,09 \\
\hline & & - Bahan baku mudah tersedia & 0,03 & 3 & 0,09 \\
\hline & & - Harga bahan baku terjangkau & 0,03 & 3 & 0,09 \\
\hline & & - Pembelian bibit jamur mudah didapat & 0,04 & 3 & 0,12 \\
\hline & & - Pembelian bibit jamur terjangkau transportasi & 0,04 & 3 & 0,12 \\
\hline & & - Pembelian bibit jamur berkualitas & 0,04 & 3 & 0,12 \\
\hline & & - Harga pembelian bibit jamur terjangkau & 0,04 & 3 & 0,12 \\
\hline \multirow[t]{3}{*}{2.} & \multirow[t]{3}{*}{ HASIL PANEN } & - Mudahnya proses pemanenan & 0,04 & 3 & 0,12 \\
\hline & & - Kualitas jamur tiram bersifat organik & 0,04 & 4 & 0,16 \\
\hline & & - Hasil panen dijamin bersih & 0,04 & 3 & 0,12 \\
\hline
\end{tabular}

Volume 20 Nomor 2 September 2019, AGRI-TEK | 63 
Website : http://agritek.unmermadiun.ac.id/index.php/agritek

\begin{tabular}{|c|c|c|c|c|c|}
\hline & & - Jumlah hasil panen banyak & 0,03 & 2 & 0,06 \\
\hline & & - Dapat dipanen 5-7 kali & 0,02 & 2 & 0,04 \\
\hline & & & 0,46 & & 1,34 \\
\hline & ELEMAHAN & & BOBOT & RATING & SKOR \\
\hline 1. & BAHAN BAKU & - Ketergantungan terhadap bahan baku utama & 0,03 & 3 & 0,09 \\
\hline 2. & HASIL PANEN & - Hasil panen yang tidak stabil & 0,04 & 3 & 0,12 \\
\hline & & - Hasil panen yang tidak bertahan lama & 0,04 & 3 & 0,12 \\
\hline 3. & SDM & - Kurangnya pengetahuan budidaya jamur tiram & 0,03 & 3 & 0,09 \\
\hline & & - Motivasi dan kegigihan petani & 0,04 & 4 & 0,16 \\
\hline 4. & MODAL & - Modal terbatas & 0,04 & 4 & 0,16 \\
\hline & & - Belum adanya bantuan dari dinas terkait & 0,04 & 3 & 0,12 \\
\hline 5. & TEKNOLOGI & - Tidak adanya teknologi modern & 0,03 & 3 & 0,09 \\
\hline & & - Pengetahuan teknologi petani masih kurang & 0,03 & 3 & 0,09 \\
\hline 6. & PE/MASARAN & - Kurangnya pemasaran melalui media sosial & 0,03 & 3 & 0,09 \\
\hline & & - Kurang luasnya pangsa pasar yang dilakukan & 0,03 & 2 & 0,06 \\
\hline 7. & KEMITRAAN & - Belum adanya kemitraan & 0,04 & 3 & 0,12 \\
\hline & & - Pemberdayaan kemitraan & 0,03 & 3 & 0,09 \\
\hline 8. & LEMBAGA & - Belum adanya bimbingan dan pengawasan pemerintah & 0,04 & 3 & 0,12 \\
\hline & PEMERINTAH & - Belum adanya kebijakan pemerintah & 0,04 & 3 & 0,12 \\
\hline & & & $\mathbf{0 , 5 4}$ & & 1,64 \\
\hline
\end{tabular}

Sumber : (Data diolah, 2019)

Hasil analisis untuk faktor internal memiliki nilai kekuatan dan kelemahan budidaya jamur tiram di Kabupaten Magetan. Nilai kekuatan menunjukkan skor 1,34 sedangkan nilai kelemahan menunjukkan nilai 1,64. Sedangkan matrik IFAS didapatkan budidaya jamur tiram memiliki kelemahan daripada kekuatan. Sehingga diperlukan strategi untuk mengubah kelemahan menjadi kekuatan. Seperti perlunya bimbingan dan pelatihan bagi petani jamur, penggunaan teknik rotasi dan teknik refresh untuk mengantisipasi panen yang bersamaan, penggunaan teknologi yang menunjang efisiensi dalam produksi maupun budidaya, peningkatan hasil panen guna meningkatkan pemasaran untuk memenuhi permintaan konsumen, mengumpulkan beberapa pelaku usaha jamur tiram untuk membentuk komunitas dan kemitraan serta pengajuan bantuan dan pengarahan dalam pengembangan bisnis.

\begin{tabular}{|c|c|c|c|c|c|}
\hline \multirow{2}{*}{\multicolumn{3}{|c|}{ FAKTOR - FAKTOR EKSTERNAL }} & \multirow{3}{*}{$\begin{array}{c}\begin{array}{c}\text { BOBOT } \\
\text { (a) }\end{array} \\
0,18\end{array}$} & \multirow{2}{*}{$\begin{array}{l}\text { RATING } \\
\text { (b) }\end{array}$} & \multirow{2}{*}{$\begin{array}{l}\text { SKOR } \\
(\mathbf{a} \times \mathbf{x} b)\end{array}$} \\
\hline & & & & & \\
\hline \multirow[t]{2}{*}{1.} & \multirow{2}{*}{ MANFAAT JAMUR TIRAM } & - Kesadaran masyarakat akan makanan sehat & & 3 & 0,54 \\
\hline & & - Bahan substitusi daging/ayam & 0,15 & 3 & 0,45 \\
\hline 2. & TEKNOLOGI & - Teknologi yang semakin pesat & 0,13 & 2 & 0,26 \\
\hline 3. & PESAING & - Adanya pesaing & 0,18 & 3 & 0,54 \\
\hline \multicolumn{3}{|c|}{ Total } & 0,64 & & 1,79 \\
\hline \multicolumn{3}{|c|}{ B. ANCAMAN } & BOBOT & RATING & SKOR \\
\hline 1. & CUACA & - Cuaca yang tidak menentu & 0,18 & 3 & 0,54 \\
\hline 2. & HAMA & - Serangan hama dan kontaminasi & 0,18 & 3 & 0,54 \\
\hline \multicolumn{3}{|c|}{ Total } & 0,36 & & 1,08 \\
\hline
\end{tabular}

Sumber : data diolah, 2019

Berdasarkan tabel diatas menunjukkan hasil analisis eksternal untuk faktor peluang dan faktor ancaman. Didapatkan nilai skor faktor peluang adalah 1,79 sedangkan nilai skor faktor ancaman sebesar 1,08. Sehingga didapatkan budidaya jamur tiram di Kabupaten Magetan memiliki peluang yang lebih besar daripada ancaman. Peluang usaha budidaya jamur tiram yaitu kesadaran masyarakat akan hidup sehat dengan makanan organik serta sebagai subtitusi pengganti daging atau ayam.Peluang ini menjadikan keuntungan yaitu meningkatnya permintaan konsumen serta minimnya pesaing jamur tiram di Kabupaten Magetan hal ini dapat meningkatkan produktifitas. Peluang ini lebih besar lagi dengan diimbangi penggunaan teknologi. Teknologi modern sangat dibutuhkan sebagai penunjang baik selama budidaya jamur tiram hingga pemasaran. Sedangkan untuk mengantisipasi ancaman yaitu cuaca dan hama maka diperlukannya pencegahan seperti penyesuaian suhu dan kelembaban dengan buka tutup sirkulasi udara, pembersihan kumbung dan baglog secara rutin serta penyemprotan insektisida secara berkala

Hasil dari matrik IFE dianalisis kembali untuk mengetahui posisi pemetaan budidaya saat ini. seperti disajikan pada Gambar.1 


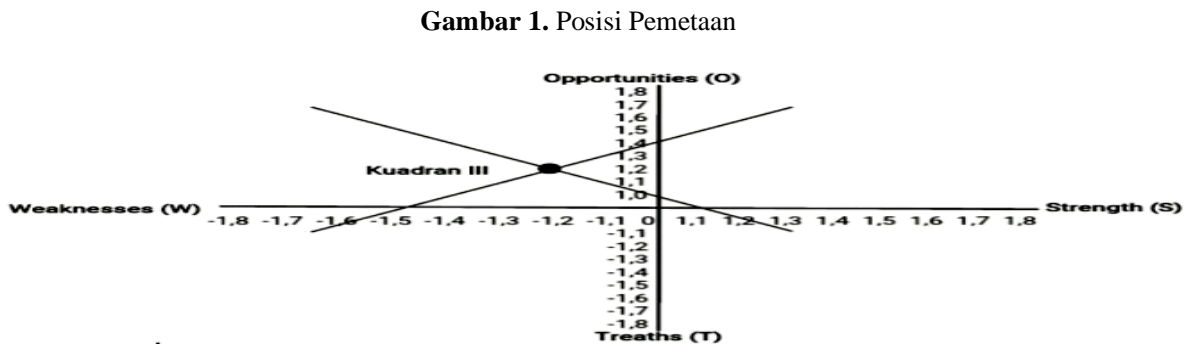

Sumber : data diolah, 2019)

Berdasarkan gambar diatas diketahui bahwa budidaya jamur tiram di Kabupaten Magetan berada pada posisi pemetaan kuadran III. Kuadran III bernilai (negatif, positif), dengan titik temu pada garis Y yaitu opportunities positif dengan garis X weaknesses negatif. Posisi ini menandakan usaha budidaya jamur tiram yang lemah namun sangat berpeluang. Rekomendasi strategi yang diberikan adalah ubah strategi, artinya organisasi disarankan untuk mengubah strategi sebelumnya agar dapat memperbaiki keadaan yang dikhawatirkan sulit untuk dapat menangkap peluang seperti disajikan pada Tabel 3 .

\begin{tabular}{|c|c|c|}
\hline \multicolumn{3}{|c|}{ Tabel 3. Matrik SWOT } \\
\hline Faktor Eksternal & $\begin{array}{l}\text { Strength (S) } \\
\text { - Bahan baku mudah didapat } \\
\text { - bahan baku terjangkau transportasi } \\
\text { - Bahan baku mudah tersedia } \\
\text { - Harga bahan baku terjangkau } \\
\text { - Bibit jamur mudah didapat } \\
\text { - Pembelian bibit jamur terjangkau } \\
\text { transportasi } \\
\text { - Pembelian bibit jamur berkualitas } \\
\text { - Harga pembelian bibit jamur terjangkau } \\
\text { - Mudahnya proses pemanenan } \\
\text { - Kualitas jamur tiram bersifat organik } \\
\text { - Hasil panen dijamin bersih } \\
\text { - Jumlah hasil panen banyak } \\
\text { - Dapat dipanen } 5 \text { - } 7 \text { kali }\end{array}$ & $\begin{array}{l}\text { Weaknesses (W) } \\
\text { - } \text { Ketergantungan terhadap bahan baku } \\
\text { utama(belum) } \\
\text { - } \text { Hasil panen yang tidak stabil } \\
\text { - } \text { Hasil panen yang tidak bertahan lama } \\
\text { - } \text { Kurangnya pengetahuan budidaya jamur tiram } \\
\text { - } \text { Motivasi dan kegigihan petani } \\
\text { - } \text { Modal terbatas } \\
\text { - } \text { Belum adanya bantuan dari dinas terkait } \\
\text { - } \text { Tidak adanya teknologi modern } \\
\text { - } \text { Pengetahuan teknologi petani masih kurang } \\
\text { - } \text { Kurangnya pemasaran media sosial } \\
\text { - } \text { Kurang luasnya pangsa pasar yang dilakukan } \\
\text { - } \text { Belum adanya kemitraan } \\
\text { - Pemberdayaan kemitraan } \\
\text { - Belum adanya bimbingan dan pengawasan } \\
\text { - pemerintah }\end{array}$ \\
\hline $\begin{array}{l}\text { Opportunities (O) } \\
\text { - Kesadaran masyarakat akan } \\
\text { makanan sehat } \\
\text { - Bahan substitusi daging/ayam } \\
\text { - Teknologi yang semakin pesat } \\
\text { - Minim pesaing }\end{array}$ & $\begin{array}{l}\text { Strategi (SO) } \\
\text { - Peningkatan jumlah baglog disertai } \\
\text { kualitas baglog dan kualitas bibit jamur } \\
\text { - Pemanfaatan teknologi alsintan }\end{array}$ & $\begin{array}{l}\text { Strategi (WO) } \\
\text { - Penerapan manajemen dan SDM yang berkualitas } \\
\text { - Menjalin hubungan dengan kelompok tani, } \\
\text { kemitraan, investor dan dinas terkait. } \\
\text { - Memperluas jangkauan pangsa pasar dan } \\
\quad \text { pemanfaatan teknologi dalam pemasaran }\end{array}$ \\
\hline $\begin{array}{l}\text { Treaths }(\mathbf{T}) \\
\text { - Cuaca yang tidak menentu } \\
\text { - Serangan hama dan kontaminasi }\end{array}$ & $\begin{array}{l}\text { Strategi (ST) } \\
\text { - Peningkatan kualitas baglog dan kualitas } \\
\text { bibit jamur. } \\
\text { - Peningkatan perawatan budidaya jamur } \\
\text { tiram }\end{array}$ & $\begin{array}{l}\text { Strategi (WT) } \\
-\quad \text { Penerapan kemampuan SDM yang berkualitas }\end{array}$ \\
\hline
\end{tabular}

Sumber : (Data diolah, 2019

Berdasarkan hasil analisis matriks SWOT diperoleh beberapa alternatif strategi yaitu strategi SO, strategi WO, strategi ST dan strategi WT. Penjelasan alternatif strategi tersebut adalah sebagai berikut :

\section{A. Strategi $S-O$}

Alternatif SO adalah alternatif yang diberikan setelah tingkat kekuatan dan tingkat peluang diobservasi. Budidaya jamur tiram di Kabupaten Magetan memiliki kekuatan pada faktor bahan baku dan bibit terhadap peluang permintaan konsumen yang cukup tinggi tetapi belum bisa dipenuhi oleh produktifitas panen jamur tiram. Dengan peningkatan jumlah baglog disertai kualitas baglog dan bibit jamur diharapkan mampu meningkatkan jumlah miselium yang penuh dan tumbuh lebih lama sehingga dapat meningkatkan jumlah produktifitas hasil panen. Selain itu adanya teknologi alsintan yang hingga saat ini belum digunakan oleh petani jamur. Alat yang digunakan adalah alat sederhana dan cukup terjangkau seperti pengaduk manual dalam 
Website : http://agritek.unmermadiun.ac.id/index.php/agritek

pencampuran bahan baku baglog, pengemasan baglog secara manual sehingga dikhawatirkannya belum merata atau terlalu renggang maupun padat, serta penggunaan drum minyak untuk pengukusan baglog. Tetapi dengan adanya teknologi alsinta mempermudah secara efisien dan efektif dalam mengembangan budidaya jamur tiram yang lebih luas lagi.

\section{B. Strategi $W-O$}

Analisis strategi WO adalah alternatif strategi yang diberikan untuk mengatasi kelemahan dengan peluang jamur tiram. Kualitas SDM baik pengetahuan dan kemampuan petani jamur tiram dengan penggunaan teknologi yang modern memberikan kemudahan petani jamur dalam memanajemen dan menghadapi ancaman dikemudian hari. Serta perlunya menjalin hubungan dengan kelompok tani, kemitraan, investor atau dinas terkait agar diberikan arahan dan bimbingan untuk menghasilkan perubahan yang lebih baik dari segi budidaya jamur tiram, perluasan jangkauan pangsa pasar dan pemanfaatan teknologi dalam pemasaran. Selama ini budidaya jamur tiram dilakukan sesuai pengetahuan petani yang sebelumnya belajar secara pribadi maupun belajar budidaya melalui rekan petani jamur tiram. Penjualan jamur tiram secara langsung ke tengkulak atau pengepul yang didatangi setiap pagi menjelang subuh hasil panen tengah malam. Penjualan jamur tiram ini belum mampu memenuhi permintaan konsumen dikarenakan hasil panen yang tidak stabil sehingga sampai saat ini belum adanya pemanfaatan teknologi dalam pemasaran hasil panen yaitu jamur tiram.

\section{Strategi $S-T$}

Strategi ST adalah strategi yang dihasilkan dari adanya kekuatan dan ancaman. Kekuatan yang dimiliki jamur tiram yaitu terjangkaunya bibit dan bahan baku yang ada untuk menghasilkan kualitas jamur tiram melalui peningkatkan kualitas bibit dan baglog jamur tiram. Hal ini untuk mengatasi ancaman seperti cuaca yang tidak menentu dan adanya hama. Hasil tumbuh buah jamur tiram diharapkan berkualitas sesuai standart dan meningkatnya produktifitas jamur tiram dalam memenuhi kebutuhan konsumen.

Peningkatan kualitas bibit jamur berbanding lurus terhadap kualitas baglog yang dihasilkan didukung dengan metode yang benar. Selama ini yang menjadi kendala dalam budidaya jamur tiram salah satunya adalah baglog yang dihasilkan terkontaminasi bahkan gagal menjadi bibit tumbuh jamur. Dikarenakan kulitas bibit jamur f2 kurang baik untuk diturunkan ke f3 yaitu baglog serta pengetahuan petani jamur dalam manajemen saat pembuatan baglog hingga baglog siap ditumbuhi miselium serta perawatan selama budidaya jamur .

\section{Strategi $W-T$}

Alternatif strategi WT adalah alternatif strategi yang ditawarkan dengan melihat kondisi budidaya jamur tiram dari faktor kelemahan dan ancaman yang terjadi. Beberapa kelemahan pada budiaya jamur tiram di Kabupaten Magetan diatasi dengan penerapan kualitas petani jamur agar dapat memanajemen dan melakukan perawatan dari pembuatan baglog sampai pemanenan dengan baik dan tepat. Hal ini diharapkan dapat mengatasi adanya ancaman yaitu hama dan kontaminasi serta cuca yang tidak menentu. Selama ini petani jamur mengatasi hama dan kontaminasi jamur dengan pembersihan baglog yang terkena hama dan kontaminasi seperti tumbuhnya jamur lain bahkan membiarkan baglog tersebut. Sehingga hasil panen tidak stabil bahkan terkadang gagal panen. Selain itu mengatasi cuaca yang tidak menentu, petani jamur menyiram area kumbung jamur dan baglog.

\section{E. Analisis Hirarki Proses (AHP)}

Analisis hirarki proses merupakan analisis kuantitaif digunakan untuk mengindentifikasi nilai perbandingan dari menentukan goal, perbandingan bobot kriteria dan perbandingan nilai bobot alternatif strategi disetiap faktor. Data yang telah terkumpul dari wawancara maupun observasi kemudian diuji menggunakan analisis Expert Choice 11.

Hirarki I adalah goal atau tujuan dari penelitian ini adalah Strategi Pengembangan Budidaya Jamur Tiram di Kabupaten Magetan. Hirarki II yaitu membandingkan antar faktor yang ditentukan. Faktor yang dipilih yaitu faktor tertinggi dari setiap faktor kekuatan, kelemahan, peluang dan ancaman. Didapatkan hasil dari keseluruhan responden

Gambar 2. Nilai prioritas antar factor

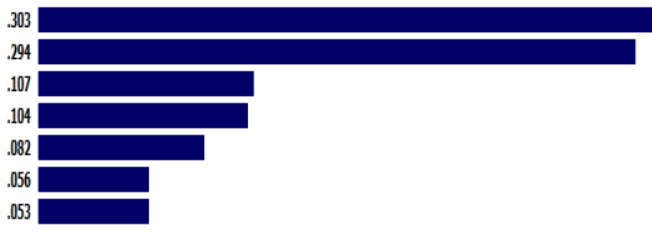


Website : http://agritek.unmermadiun.ac.id/index.php/agritek

Faktor modal, motivasi dan kegigihan serta hama merupakan faktor yang memiliki kepentingan lebih tinggi diantar faktor lainnya. Permasalahan modal yang menjadi salah satu faktor penting selain motivasi dan kegigihan petani (Fatria, 2017; Dimyati dan Astarina, 2016; Shirur dan Chandregowda, 2017) dan penanggulanan hama (Retnaningsih dan Bambang, 2017). Modal merupakan pondasi penting dalam membangun untuk memulai bahkan mengembangkan sebuah usaha. Modal bisa disebut sebagai aspek keuangan sebagai faktor kekuatan untuk membiayai operasional usaha (Fatria, 2017) dan diperlukan setiap proses produksi (Dimyati dan Astarina, 2016; Shirur dan Chandregowda, 2017) sehingga mempengaruhi peningkatan pendapatan dan produktivitas (Meisthya dan Sudirman, 2014). Semakin besar modal untuk berinvestasi dalam suatu usaha maka semakin besar pertumbuhan ekonomi, sehingga dapat meningkatkan pendapat melalui usaha yang lebih berkembang (Kholis $\mathrm{dkk}, 2016)$.

Motivasi dan kegigihan petani jamur tiram saling berpengaruh terhadap modal dan hama. Jika faktor ini memiliki kekuatan cukup besar maka dapat mengatasi adanya kelemahan seperti kurangnya modal dan hama. Motivasi dan kegigihan mempengaruhi kinerja petani jamur untuk lebih mengoptimalkan manajemen dan SDM. Hal ini dikarenakan motivasi dan kegigihan membuat diri lebih antusias (Fachreza dkk, 2018) dan mendorong kemampuan untuk mencapai tujuan (Aprilia, 2018). Kemampuan ini baik pengetahuan maupun pengalaman yang dapat mempengaruhi kualitas dan kuantitas produk (Fatria, 2017).

Hasil analisis selanjutnya adalah alternatif strategi dengan nilai prioritas berdasarkan perbandingan antar alternatif dari hasil Matrik SWOT setiap faktor. Berikut nilai prioritas alternatif yang didapatkan dari 13 responden.

Gambar 3. Nilai prioritas alternatif

Combined instance - Synthesis with respect to: Goal: STRATEGI PENGEMBANGAN BUDIDAYA JAMUR TIRAM DI KABUPATEN MAGETAN

Overall Inconsistency $=02$
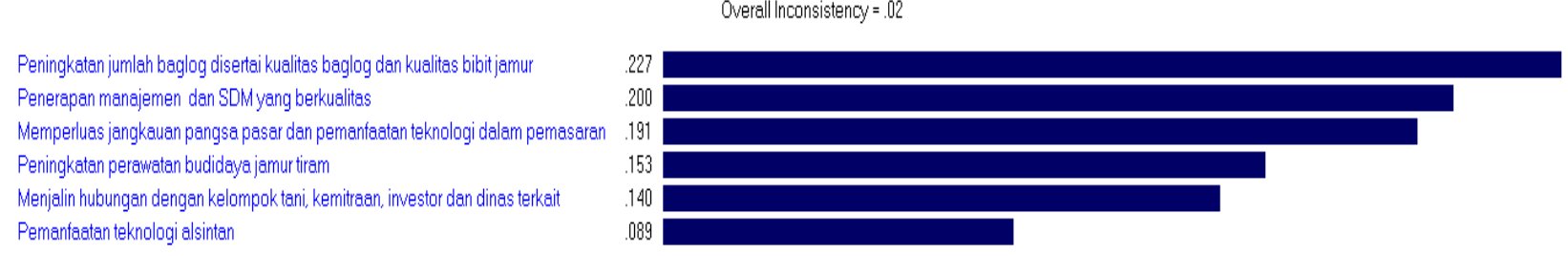

Alternatif yang memiliki nilai prioritas tertinggi yaitu pada alternatif peningkatan jumlah baglog disertai kualitas baglog dan kualitas bibit jamur sebesar 0,227, alternatif kedua yaitu penerapan manajemen dan SDM yang berkualitas sebesar 0,200 dan memperluas pangsa pasar dan pemanfaatan teknologi dalam pemasaran sebesar 0,1991 sebagai alternatif ketiga. Alternatif pertama berhubungan dengan faktor modal sebagai faktor kelemahan dan berhubungan dengan alternatif ketiga yaitu memperluas pangsa pasar dan pemanfaatan teknologi dalam pemasaran. Pemasaran jamur tiram diharapkan tidak hanya bentuk mentah tetapi perlunya pengolahan jamur tiram (Retnaningsih dan Bambang, 2017; Suriawiria, 2002; Sumarsih, 2010). Hal ini pengolahan pascapanen dapat meningkatkan perdapatan (Fatria, 2017).

Peningkatan baglog dapat memenuhi permintaan konsumen cukup tinggi tetapi belum mampu terpenuhi oleh petani jamur (Suriawiria, 2002). Sehingga selain menjadi peluang besar untuk meningkatkan pendapat juga dapat dijadikan penambahan modal yang dibutuhkan dengan memperluas pangsa pasar dan pemanfaatan teknologi dalam pemasaran. Selain itu perlunya alternatif ketiga yaitu penerapan manajemen dan SDM yang berkualitas. Penerapan yang tepat dalam peningkatan jumlah baglog diharapkan mampu menyeimbangkan proses untuk mendapatkan hasil yang maksimal dalam dapat mengoperasional budidaya jamur tiram dengan baik, menangkap peluang dengan tepat dan mampu mengatasi segala kendala yang terjadi. Sehingga didapatkan kualitas dan kuantitas produk (Fatria, 2017).

\section{F. Kelebihan kombinasi analisis SWOT dan AHP}

1. Analisis SWOT merupakan analisis sedangkan dengan AHP ditujukan untuk membuat model yang lebih mendalam dan tidak terstruktur/terukur. Sehingga didapatkan pengambilaan keputusan yang terarah (Ma'arif dan Tanjung, 2003).

2. Analisis SWOT menghasilkan bobot faktor yang tidak dikuantifikasi terhadap pengaruh setiap faktor terhadap alternatif strategi yang diajukan (Yuksel and Dagdeviren, 2007) dengan AHP dapat menentukan konsistensi logis dari berbagai prioritas dan mempertimbangkan prioritas-prioritas relatif serta menentukan alternatif. Selain itu, AHP dianalisis dengan penyusunan hirarki berdasarkan tujuan utama yang ingin dicapai (Saaty, 1993).

3. Analisis SWOT merupakan metode kualitatif deskriptif dan AHP merupakan metode kuantitatif. Sehingga kombinasi ini memberikan hasil yang optimal. Pun dan Hui (2001) menjelaskan bahwa proses perumusan strategi melalui tiga tahap, yaitu analisis IFAS dan EFAS, matrik SWOT dan analisis AHP.

4. Kombinasi SWOT dengan AHP memberikan hasil lebih detil dan komprehensif melalui faktor-faktor pada SWOT yang berpengaruh besar dalam peroleh skor yang benar-benar diyakini mampu mendukung alternatif yang dipilih oleh AHP (Dekiawan dan Hasan, 2018). Selain itu dasar AHP menghasilkan keputusan yang rasional dan efektif (Saaty, 1993). 
Website : http://agritek.unmermadiun.ac.id/index.php/agritek

5. Alternatif yang ditentukan melalui matrik IFE atau SWOT tidak dapat diterapkan bersamaan dikarenakan beberapa faktor yang terkait seperti keterbatasan sumber daya yang tidak selalu tersedia. Tetapi dengan AHP menghasilkan nilai prioritas setiap alternatif sehingga dapat digunakan untuk memperkirakan nilai efisiensi strategi yang tetapkan (Osuna et al, 2007).

\section{IV.KESIMPULAN}

Kesimpulan yang dapat diperoleh dalam penelitian ini mengenai budidaya jamur tiram di Kabupaten Magetan adalah :

1. Faktor yang berpengaruh pada budidaya jamur tiram di Kabupaten Magetan adalah pada faktor internal yaitu hasil panen yang bersifat, faktor modal terbatas dan faktor motivasi dan kegigihan petani. Faktor eksternal yaitu manfaat jamur tiram yaitu kesadaran masyarakat akan makanan sehat, cuaca dan hama.

2. Alternatif yang memiliki nilai prioritas tiga tertinggi yaitu pada peningkatan jumlah baglog disertai kualitas baglog kualitas bibit jamur, penerapan manajemen dan SDM yang tepat, dan memperluas jangkauan pangsa pasar dan pemanfaatan teknologi dalam pemasaran.

\section{UCAPAN TERIMAKASIH}

Penulis mengucapkan terima kasih Dinas Pertanian Magetan, Petani Jamur Tiram Kabupaten Magetan dan para Dosen Pembimbing yang telah mendukung selama penelitian.

\section{VI.DAFTAR PUSTAKA}

Alie, Mahrus. 2011. Strategi Penataan Kawasan Peternakan di Wilayah Perkotaan dan Konsekuensinya Terhadap Usaha Ternak Sapi Potong. Jurnal Manajemen Agribisnis Vol. 11 No. 3 Jui 2011.

Aprilia, Lu'luwatin Rosdiana. 2018. Pengaruh Kemampuan dan Motivasi Kerja Terhadap Kinerja Karyawan di Hotel Isola Resort dan Meeting Services. Tourism and Hospitality Essentials (THE) Journal, Vol. 8, No. 1, 2018 - 15.

BPS. 2019. Badan Pusat Statistik (BPS). https://www.bps.go.id/.

Dekiawan, Hermada dan Hasan Subagyo. 2018. Simulasi Model Swot-AHP dalam Penentuan Pilihan Alternatif Strategi Pengembangan Perguruan Tingg Vokasi D3. Erudio (Journal of Educational Innovation), 5(1), June 2018.

Dimyati, Laili dan Astarina Yesita. 2016. Strategi Pengembangan Usaha Jamur Tiram Putih di Kota Pagaralam. Seminar Nasional Teknologi Informasi, Bisnis, dan Desain 2016. STMIK-Politeknik PalComTech, 12 Mei 2016.

Evalia, Nur Afni. 2015. Strategi Pengembangan Agroindustri Gula Semut Aren. Jurnal Manajemen dan Agribisnis, Vol. 12 No. 1, Maret 2015.

Fachreza, Said Musnadi, M. Shabri, dan Abd Majid. 2018. Pengaruh Motivasi Kerja, Lingkungan Kerja, dan Budaya Organisasi Terhadap Kinerja Karyawan dan Dampaknya Pada Kinerja Bank Aceh Syariah di Kota Banda Aceh. Jurnal Magister Manajemen ISSN 2302-0199 Fakultas Ekonomi dan Bisnis Unsyiah pp. 115-122 Volume 2, No. 1, Januari 2018-115.

Fatria, Muhammad Akbar. 2017. Strategi Pengembangan Industri Rumahtangga di Kota Pekanbaru (Studi Kasus Usaha Jamur Crispy Industri Pengolahan Jamur Tiram). JOM Fekon, Vol.4 No.1 (Februari) 2017.

Gunawan Yunus dan Adi Permadi. 2015. Strategi Pengembangan Industri Kecil Carica. Journal of Economics and Policy, Maret 2015.

Iqbal, M., dan Sudaryanto. 2008. Tanggung Jawab Sosial Perusahaan (Corporate Social Responsibility) dalam Perspektif Kebijakan Pembangunan Pertanian. Jurnal Analisa Kebijakan Pertanian. 6(2), 155-173.

Jumna, Dasudewo Krisna. 2015. Strategi Pengembangan Usahatani dalam Upaya Peningkatan Produksi Padi Organik. Economics Development Analysis Journal

Kholis, Muhammad., Diah Astuti, dan Rini Febrianti. 2016. Hubungan Antara Pendapatan Nasional dan Investasi di Indonesia (Suatu Kajian Ekonomi Makro dan Model VAR). Jurnal Organisasi dan Manajemen, Volume 12, Nomor 1, Maret 2016, 65-78.

Ma'arif MS, Tanjung H. 2003. Teknik-Teknik Kuantitatif untuk Manajemen. PT Gamedia Widiasarana Indonesia, Jakarta.

Mayanja, Ibrahim dan Tipi, Tolga. 2018. A Study of The Profitability of Oyster Mushroom Cultivation in Kampala Metropolitan Area, Uganda. Custos e @ gronegocio on line v. 14, n. 4, out/Dez-2018. ISSN 1808-2882.

Meisthya Pratiwi, Ida Ayu dan Sudirman, I Wayan. 2014. Variabel yang Berpengaruh Terhadap Penyaluran Kredit Modal Usaha Mikro Kecil Menengah (UMKM) di Bali Periode 2001-2003 Jurnal Ekonomi Pembanguna Universitas Udayana.

Osuna, Edgar Elias dan Aranda, Alvaro., 2007. Combining Swot And Ahp Techniques For Strategic Planning. Economic journal. Instituto de Estudios Superiores de Administración (IESA) Avenida IESA, San Bernardino, Caracas - Venezuela.

Prastowo, Bambang. 2007. Potensi Sektor Pertanian sebagai Penghasil dan Pengguna Energi Terbarukan (The agriculture sector as source and user of the renewable energy). Indonesia Center for Estate Crops Research and Development. Perspektif: Review Penelitian Tanaman Industri 6(2): 85-93.

Pun KF, Hui IK. 2001. An analytical hierarchy process assessment of the ISO 14001 environmental management system. Integrated Manufacturing Systems, 12, 5; ABI/INFORM Complete Pg. 333.

Rahajuningsih, Eni Sri. 2011. Strategi Pengembangan Agroindustri Kurmelo di Kecamatan Sukomoro Kabupaten Magetan. Jurnal Manajemen Agribisnis Vol 11 No. 3 Jui 2011

Retnaningsih, Nugraheni dan Bambang N. C. 2017. Strategi Pengembangan Jamur Tiram (Pleurotus Ostreatus) di Kelompok Tani Aneka Jamur Desa Gondangmanis Kecamatan Karangpandan Kabupaten Karanganyar. Jurnal SEPA : Vol. 14 No.1 September 2017 : 61 - 68 ISSN : $1829-9946$.

Rompas Jui, Deisy Engka dan Krest Tolosang. 2015. Potensi Sektor Pertanian Dan Pengaruhnya Terhadap Penyerapan Tenaga Kerja di Kabupaten Minahasa Selatan. Jurnal Berkala Ilmiah Efisiensi Volume 15 No. 04 Tahun 2015.

Saaty, T.L. 1993. Proses Herarki Analitik Untuk Pengambilan Keputusan dalam Situasi yang Kompleks. Binaman Pressindo, Jakarta.

Shirur, Mahantesh dan Chandregowda MJ. 2017. Ensuring Success in Oyster (Pleurotus Sp.) Mushroom Cultivation Through Marketing Strategies - A Case Study and SWOT Analysis. Journal of Agricultural Economics and Rural Development

Sumarsih, S. 2010. Untung Besar Usaha Bibit Jamur Tiram. Penebar Swadaya. Jakarta.

Suriawiria, H. U. 2002. Budidaya Jamur Tiram. Kanisius. Yogyakarta. 
Website : http://agritek.unmermadiun.ac.id/index.php/agritek

Tirani, Yudi Sapta Pranoto, dan Haryono Moelyo. 2018. Kontribusi Sektor Pertanian berdasarkan Keunggulan Wilayah di Kabupaten Bangka. Caraka Tani: Journal of Sustainable Agriculture. 2018. 33(1), 42-49.

Utsalina, Dwi Safiroh dan Weda Adistianaya Dewa. 2015. Strategi Pemasaran Menggunakan Metode Kombinasi SWOT dan AHP. SMATIKA Jurnal Volume 05 Nomor 02 Tahun 2015 ISSN: 2087-0256 hal. 18.

Yani, Ahmad. 2011. Analisis Strategi Bisnis Perusahaan Daerah Perkebunan Margomulyo di Kabupaten Kediri. Jurnal Manajemen Agribisnis Vol. 11 No. 3 Jui 2011.

Yuksel I, Dagdeviren M (2007) Using the Analytic Network Process (ANP) in a SWOT Analysis -A Case Study for A Textile Firm. Inf Sci 177(16):33643382. 